\title{
UNA PRIMERA MIRADA AL SEGURO AMBIENTAL, TRIBUTARIO A UN DESARROLLO SOSTENIBLE COMO PARTE DE LA POLÍTICA EMPRESARIAL CUBANA
}

\author{
Alcides Antúnez Sánchez \\ Universidad de Granma, Cuba \\ Joao Domingos Víctor \\ Universidad de Oriente, Cuba
}

http://dx.doi.org/10.5209/rev_NOMA.2013.v38.42916

\begin{abstract}
Resumen.- El trabajo tiene la intencionalidad de dar una mirada al seguro ambiental dentro de la legislación cubana, para esto los autores realizan un breve análisis histórico de la actividad aseguradora en el país hasta el triunfo revolucionario. Nos apoyamos además en la ejecución de este análisis de lo relacionado con la institución del contrato de seguro, y en particular lo regulado con el seguro ambiental obligatorio en países como España, Argentina y Chile como parte del derecho comparado objeto de análisis. Realizamos un análisis de la política ambiental de Cuba, partiendo desde el texto constitucional, la actividad mercantil relacionada con política aseguradora y con la política inversionista extranjera, con un análisis de normativas jurídicas que han contextualizado el seguro en el derecho interno cubano. Nos apoyamos para ejecutar el artículo en los métodos científicos de apoyo a la investigación el histórico lógico, el exegético-jurídico, el análisis y revisión de documentos científicos tanto sociales como jurídicos.
\end{abstract}

Palabras clave.- seguro ambiental, daño ambiental, control ambiental

Abstract.- The work has the intentionality to give a look to the sure environmental within legislation Cuban, ad hoc the authors accomplish a brief historic analysis of the insurance business at the country to the revolutionary triumph. We leant besides in the execution of this analysis of the related thing with the institution of the insurance contract, and in particular what's regulated with the sure environmental at countries obligatory like Spain, Argentina and Chile as part of the compared right I raise objections of analysis. We accomplished an analysis of the environmental policy of Cuba, departing from the constitutional text, the related mercantile activity with insuring policy and with the politic foreign investor with an analysis of juridical ground ruleses, that there are contextualizado the insurance in the internal right Cuban. The historic logician, the exegetic leant to play the article in the scientific backup methods to the investigation juridical, analysis and revision of scientific documents so much social like juridical.

Keywords.- environmental insurance, environmental damage, environmental control

\section{INTRODUCCIÓN}

Este artículo tiene la intención de hacer un análisis del contrato de seguro por la comisión del daño ambiental y motivar a que susciten propuestas que busquen solucionar los problemas que surgen por su no regulación en el derecho cubano, 
haciendo para esto una comparación con los distintos sistemas de derecho en torno al seguro de las legislaciones analizadas. Consideramos necesario por los autores, comenzar con un breve estudio de la historia del seguro y de los sistemas de responsabilidad por la comisión del daño ambiental y los elementos que intervienen, ya que todo sistema de responsabilidad tiende a establecer, en último término, la reparación del daño, sin perjuicio que dentro de la responsabilidad se establezcan otros elementos, como las medidas preventivas, que maticen este carácter esencialmente reparador. Y el seguro tiene, como principal fundamento el otorgar solvencia para la reparación del daño y la protección a la víctima, concluyéndose así que los avances hacia una mayor cobertura de los riesgos por el sistema de responsabilidad dependen en gran medida de como los mecanismos aseguradores son capaces de internalizar dichos riesgos y ofrecer a los agentes de comercio y de la producción, pólizas de seguros que hagan viable el desarrollo de las actividades susceptibles de causar daños a los usuarios.

Para esto brevemente analizamos sistemas comparados de responsabilidad, el sistema norteamericano, (CERCLA) bajo el principio de "el que contamina paga", y de la Directiva del Parlamento Europeo y del Consejo sobre responsabilidad medioambiental en relación con la prevención y reparación de daños medioambientales del 2004, estudiando por último nuestro sistema regulado en la Ley No 19.300, de Bases Generales del Medio Ambiente, que consagra un sistema subjetivo de responsabilidad.

La materia medioambiental es un campo de observación privilegiado para evaluar la necesidad de establecer criterios de responsabilidad que se complementen con la necesidad de los instrumentos financieros que brindan garantía por los eventuales y a veces inevitables daños que concurren. Junto al tratamiento del riesgo ambiental en las pólizas generales, no puede faltar el estudio detallado de la cobertura del riesgo de contaminación a través de las pólizas específicas con un planteamiento de suscripción claramente especializado. Así, en el mercado de la comunidad europea que hemos analizado como derecho comparado, la fórmula que se ha ocupado es la formación de pools de cobertura de daños por contaminación.

Se analiza la póliza de seguro, que actúa como póliza de garantía y cada una de sus menciones, y se planteará la hipótesis de una posible responsabilidad objetiva, mostrándose cierto grado de incompatibilidad entonces con nuestro sistema de responsabilidad subjetiva, en el que sólo se responde si se ha actuado con dolo o culpa. Este trabajo finaliza con una idea general sobre los problemas y vacíos que se contienen en la regulación de este contrato de seguro en nuestro ordenamiento jurídico cubano, la dificultad que se presenta el ofrecer productos que sean accesibles a las empresas y otorguen una cobertura efectiva por los daños causados, y así proponer algunas medidas que entreguen una propuesta en un escenario que está sujeto a grandes transformaciones, ya que el seguro es una herramienta necesaria para el buen funcionamiento de un sistema de reparación de daños ambientales. Como su vinculación con las herramientas de gestión ambiental para su concesión por parte de la entidad aseguradora. 


\section{1.- LA ACTIVIDAD ASEGURADORA EN CUBA, TRACTO HISTORICO}

En Cuba, antes que los ingleses tomaran la Habana en 1762, el comercio de la isla se centraba en los vínculos con la corona española. Existiendo en los puertos cubanos agentes o factores, como se les denominaba entonces, de compañías españolas de seguro que reafirmaban el monopolio total de la metrópoli, como el de la "La Unión", dedicada al ramo de incendios y "El porvenir de las familias", sobre seguro de vida.

El 24 de enero de 1795 se constituye en la Habana la primera compañía de seguros en Cuba, mediante escritura pública, "Protectores y Superdirectores de la compañía a la Santísima Virgen Nuestra Señora de Regla y al señor San Cristóbal"1 implorando, según dicen los estatutos, "su patrocinio para que, como Padrinos de este establecimiento, intercedan con el Omnipotente para el buen éxito de sus empresas". Su objetivo era "los seguros marítimos generales para las cuatro partes del mundo" por considerar sus fundadores, personalidades prominentes de la Colonia, que la Habana requería aseguradores ya que "una plaza de tanto tráfico como ésta, está muy necesitada de aseguradores, que, en un caso o embarque repentino, puedan asegurar aquí sus remesas" otorgándose garantías al comerciante. Tuvo como capital social ochocientos mil pesos. Con visibilidad en los puertos de Cádiz, Barcelona, Santander, Coruña Tenerife, Guayra, Campeche, Veracruz, Trujillo, Nueva Orleáns, Cartagena y Buenos Aires.

En 1845 se constituyen las primeras agencias de compañías extranjeras ${ }^{2}$, inglesas principalmente. En 1851 se crea "La Alianza", sociedad de créditos y seguros sobre la vida de los colonos chinos y de los esclavos, desarrollando, además, el seguro marítimo. Ya en 1855 se fundan varias aseguradoras; "El Iris", primera compañía de seguros mutuo contra incendios, "La Hereditaria", dedicada a los seguros mutuos sobre la vida, y "La Providencia", sociedad de seguros sobre la vida de los esclavos, similar ramo al que se dedicó "La Protectora", creada en 1856. Salvo El Iris, estas compañías tenían carácter mixto, actuando como instituciones de seguro y crédito, con estrechas relaciones con el sistema esclavista imperante en esta época.

En 1862 comienzan a operar en el país Compañías de seguros inglesas, canadienses, americanas fundamentalmente y otras de diversas nacionalidades. Alrededor de 1882 se crea la Cía. "Lloyd Habanero", dedicada a seguros marítimos, y otra compañía dedicada a seguros de incendios, especializada en seguros. Estas surgieron con nuevas orientaciones económicas, desligadas del esclavismo, y bajo estructura de sociedades anónimas. Para esta época, y coincidiendo con el fin de la Guerra de los 10 años y por ende ya existiendo una

\footnotetext{
${ }^{1}$ MARTÍNEZ ESCOBAR, Manuel, Los Seguros. Ed. Cultural, La Habana 1945, p. 12 y 13. En la obra, el autor menciona que la escritura fue encontrada por el Dr. Francisco Henríquez Ureña en la Biblioteca de la Sociedad Económica de Amigos del País, y publicada en la revista Seguros. Cuba.

2 HENRÍQUEZ UREÑA, Francisco, "La evolución del seguro en Cuba", revista Seguros, La Habana, Año II, No. 3, marzo de 1937, p.26.
} 
reanimación económica, se produce un aumento de las compañías aseguradoras extranjeras.

Dedicadas a los seguros de vida, la historia del país refleja la creación en 1891 de las Cías. "El Fénix" y en 1895 "Círculo cosmopolita", así como la "Caja de Ahorros y socorros mutuos de los empleados y obreros de los ferrocarriles de la Isla de Cuba". Otro hecho importante en el tracto histórico del seguro lo fue la creación de la primera compañía que estableció agencia en Cuba colocando depósitos en garantías según lo establecido en la Orden Militar 181 de 1899, fue "Fidelity \& Deposit Company of Maryland". A fines del siglo XIX se comienza a ofrecer por primera vez al mercado cubano el seguro de accidentes por parte de la compañía "Norwich Union Fire Insurance Society Limited". Amparaba la póliza: muerte por lesiones dentro de 90 días, la pérdida por amputaciones de pies y manos, ó de un pié y una mano, la pérdida completa de la vista de ambos ojos o de uno, la completa inutilización temporal, ó la inutilización parcial temporal.

A raíz de la primera intervención norteamericana, surgió en la Habana una compañía de inversiones que adquirió notorio crédito y realizó numerosas operaciones de seguros personales. Las pólizas eran vencibles a seis años como máximo, pudiendo ser canceladas antes, si eran agraciadas en los sorteos que periódicamente se celebraban. Durante varios años cumplió con las escasas pólizas que se vencían, pero la llegar a los seis años no pudo cumplir pagar la cantidad de pólizas vencidas, y la compañía en sucesivas circulares que repartió a los suscriptores, tasó caprichosamente y cada vez más baja la participación a cobrar por los acreedores. Los acreedores dueños de uno o dos pólizas iniciaron varios procesos judiciales en juicio verbal (considerándose la cuantía de las pólizas), mas la única prueba era el examen de los libros de la compañía, y la contabilidad presentaba serias dificultades en su práctica, lo que impidió el efectivo proceso de liquidación.

Para 1908 se crean dos nuevas compañías; "La Nacional", de efímera vida y dedicada a los seguros de vida; y "La Mercantil", de seguros de incendio. Esta última protagonizó una encendida disputa con una asociación que en sus estatutos prohibía el reaseguro y coaseguro, por lo que su presidente impidió su entrada en el seno de la misma. La Mercantil obtuvo reaseguro de la "Home" y de "Hartford", ambas norteamericanas, las que por su influencia en Londres lograron que el "Fire Offices Comitte Foreing" (Comité de compañías británicas para el negocio extranjero) enviara un representante para que se reorganizara la asociación sobre bases nuevas que permitieran la cooperación entre asociados, renunciando el respetado pero recalcitrante presidente, lográndose la entrada de "La Mercantil" y con ello una nueva etapa de los seguros en Cuba al renacer sobre firmes bases el seguro a prima fija y la cooperación entre aseguradores.

En el área de transporte automotor, la primera compañía que ofertó seguro de automóviles fue la norteamericana "United States Lloys, de Nueva York", en 1911. Se ofrecía en seguro $A$ y $B$, este último cubría, además de los daños recibidos por choque, los ocasionados de carácter material de que legalmente fuese 
responsable el asegurado, por lo que cubría al asegurado de su misma negligencia y hasta de su culpa. El periodo de la Primera Guerra Mundial favoreció a los países neutrales por la calma política y el incremento comercial que buscaba llenar el vacío de Europa. En 1915 se aprueba la primera ley del seguro de accidentes del trabajo, lo que generó un movimiento de creación de compañías que ofrecieran los seguros regulados. Así, para entre los años 1915 y 1919 se crearon numerosas aseguradoras, como la "Unión Hispano-Americana" organizada por los financieros del Banco Español, "Cuba", "La Cubana", "Unión Nacional", "Metropolitana", "Internacional", "Comercial", "Unión Agrícola", "Federal", "Alianza", "La Mutua", todas en la Habana. En otras ciudades fueron creadas "Cienfuegos", "Sagua", "Oriente" y "Unión Antillana". En ellas prevaleció el sistema de la multiplicidad de líneas de seguro al incluir incendios, marítimo algunas, automóvil, vida y hasta los accidentes de trabajo.

Un momento de riqueza y esplendor, es en la denominada época de las vacas gordas, se refleja en la Unión Hispano-Americana, La Cubana y Metropolitana llegaron a establecer sucursales en EE.UU. y Gran Bretaña. Para el año 1920, el derrumbe de los precios del azúcar y la consiguiente caída económica y de la banca, debilitó pero no derrumbó al sistema asegurador. Solo quebraron Internacional, atada a la caída del Banco Internacional a cuyos negocios estaba estrechamente ligada; y Cuba, compañía que operó en el ramo de incendios, vida y seguros obreros, y a la que las desventajosas soluciones oficiales que se aplicaban a las compañías de seguros obreros y deficiencias administrativas de sus intereses llevaron a la quiebra. Al cierre de ese año, las compañías cubanas controlaban del $16-18 \%$ del total anual de primas de seguro de incendio, y casi el $60 \%$ de las correspondientes a accidentes de trabajo.

En el año 1929, según estudio de la Comisión Nacional de Estadísticas y Reformas Sociales ${ }^{3}$, las primas de seguros recaudadas por compañías nacionales y extranjeras, en ramos de vida, incendio, automóviles, marítimos y cristales. Según estadísticas consultadas de la Secretaría de Comercio, al cierre 31 de diciembre de 1935, las compañías de seguro de vida poseían más de 26 millones de pesos en reservas, pero de ellos, unos 25 millones se encontraban invertidos fuera del país. En enero de 1937 se encontraban autorizadas 32 compañías cubanas de seguros ${ }^{4}$. En 1940 se encontraban autorizadas a operar 95 compañías de seguros $^{5}$, de cinco países. Al cierre de $1954^{6}$ operaban 162 compañías de seguro y 5 de reaseguros, y al de $1955^{7}$ eran 154 y 6 compañías $^{8}$,

\footnotetext{
${ }^{3}$ WOLTER DEL RíO, Germán (1886-1953): Informe y Proyecto de ley de seguros elevado al honorable Presidente de la República por la Comisión Económica. La Habana, 1931.

${ }^{4}$ Gaceta Oficial de fechas 7, 8, 9 y 22 de enero 1937.

5 "Compañías de seguros autorizadas", Revista S.B.B., Año 1, No. 3, septiembre 1ro. de 1940, p. 24 y 25

${ }^{6}$ MONTALVO, J.G.; Anuario Financiero 1954. La Habana, 1954.

${ }^{7}$ MONTALVO, J.G.; Anuario Financiero 1955. La Habana, 1955.

${ }^{8}$ Existe discrepancias con el número exacto, existen autores que dan una cifra diferente a la que aparece en el Anuario Financiero 1955, V. gr. CAMACHO RODRÍGUEZ, Tatiana, en "El seguro en Cuba, antecedentes, desarrollo y perspectivas", Revista Cubana de Derecho, No. 33, Año XVII, La
} 
respectivamente. En 1955, las compañías cubanas tenían una participación en el mercado de aproximadamente el 50\% del total de negocios por concepto de pólizas suscritas, llegando a ingresar 10,4 millones de pesos por concepto de primas cobradas ${ }^{9}$.

Por lo que los autores consideran que a pesar de que el acta de nacimiento del Derecho Ambiental, data del año 1969, las normativas cubanas dictadas no estuvieron enfocadas a la protección de los recursos naturales, aunque en la historia del Estado y del Derecho en Cuba, encontremos algunas normativas de orden administrativo que entraron a regular el uso de recursos naturales, como fue el caso del agua en la actual capital del país, y el enfoque del seguro estaba muy vinculado a la actividad comercial fundamentalmente.

Al triunfo de la Revolución como nuevo proyecto social, muchas de las compañías que operaban en nuestro territorio cerraron, o se mantuvieron inactivas y provocaron una situación de caos en el mercado que exigió la intervención directa del Gobierno Revolucionario para proteger los intereses de los asegurados y del propio país. Entre los problemas principales presentados estaban las protecciones de reaseguro que requerían los aseguradores cubanos y extranjeros, ya que las mismas estaban contratadas con reaseguradores norteamericanos o a través de sus casas matrices en los Estados Unidos. Tales protecciones fueron automáticamente canceladas a raíz de las primeras nacionalizaciones, lo cual provocó que estas compañías dejaran de suscribir nuevos riesgos, al no contar con reaseguro para sus excedentes. Asimismo, muchos ejecutivos y personal especializado de seguros abandonaron el país, dejando a las compañías totalmente inoperantes.

En el año 1959 funcionaban 52 instituciones, de seguro social, denominadas "cajas", "fondos", "cajas de retiro" o "seguros", clasificadas por la Junta Nacional de Economía, en: "jubilaciones y pensiones del Estado", "seguros profesionales" y "seguros de los trabajadores". Con los cambios ocurridos en la vida política y económica del país la seguridad social adquirió un nuevo sentido. En este campo los objetivos del programa comprendieron de inmediato la atención financiera a los fondos de los seguros sociales existentes para garantizar el cumplimento de sus obligaciones sin interrupción y a más largo plazo, la cobertura de todos los riesgos, la extensión de la protección a todos los trabajadores, la concesión de prestaciones suficientes, la racionalización y unidad administrativa, la gratuidad del sistema y la creación del seguro de enfermedad.

\footnotetext{
Habana, plantea que "En noviembre de 1955 el negocio del seguro en Cuba lo ejercían 149 compañías: de ellas, 69 cubanas, 36 inglesas, 31 norteamericanas, 6 canadienses, 2 suizas, 2 brasileras, una española, una irlandesa y una australiana, aunque en las más poderosas los intereses se hallaban entremezclados y ocultos en muchos casos, bajo el manto de sociedades anónimas".

${ }^{9}$ Esto representó un aumento del significativo con respecto a 1939, año en que participación de las compañías cubanas en el mercado era del 37,5\% por concepto de pólizas suscritas, y se cobró 10,4 millones de pesos por concepto de primas.
} 
El propósito consistía en aplicar medidas encaminadas a iniciar una justa protección y redistribución del ingreso en concordancia con la línea económicosocial que caracteriza la acción inmediata del Gobierno. El país enfrentó situaciones que, aún significando un crecimiento importante del gasto social, era preciso realizar sin aplazamiento. Los primeros pasos se encaminaron a la transformación organizativa de los seguros sociales. Detrás quedaron los intereses políticos que habían frenado durante años la unificación. La nueva organización, basada en el principio de unidad, se realizó gradualmente. El proceso comienza en el sector laboral, constituido por los seguros sociales de mayor homogeneidad.

Para el mes de mayo de 1959 se crea el "Banco de los Seguros Sociales de Cuba" (BANSESCU) como organismo autónomo encargado del gobierno y ejecución de los seguros sociales, al que se incorporaron las veinte cajas de retiro del expresado sector. Se extinguen a partir de ese momento las funciones de sus directorios, así como se transfieren a BANSESCU el patrimonio de dichas instituciones. El objetivo, asegurar la unidad de la administración y extender después el régimen a los trabajadores desprovistos de amparo. En diciembre de ese mismo año se dispuso de una Ley, incorporando un $40 \%$ aproximadamente de la población activa, quedando pendiente para normas posteriores establecer el régimen de prestaciones de los nuevos asegurados.

La Ley 851 de 1960 decreta la nacionalización de casi 50 agencias norteamericanas de seguro radicadas en Cuba, declarándose adjudicadas al Estado Cubano y se designa para su administración al Banco de Seguros Sociales de Cuba. Se crea a fines del propio año la Oficina de Control de Seguros para regir todos los negocios desarrollados por las entidades aseguradoras. En septiembre de 1962, considerando las observaciones y sugerencias atendibles como resultado de un amplio proceso de análisis y discusión realizado por los trabajadores, se elaboró definitivamente una Ley de Seguridad Social, cuyo campo de aplicación se extendió a todos los trabajadores y más de 250 mil trabajadores agrícolas quedaron comprendidos en el nuevo sistema. A partir de ese momento los trabajadores quedaban protegidos de todas las contingencias. Se fijaron pensiones decorosas y subsidios adecuados a la labor y al salario del trabajador, se otorgó además el derecho a la asistencia médica y hospitalaria en los casos necesarios. Es criterio consensuado de los autores que a partir del triunfo del proyecto revolucionario que el Estado se ocupa con las primeras leyes revolucionarias, en este caso las concernientes a la reforma agraria, de dar una mirada a la protección de los recursos naturales. El 9 de abril de 1963 se creó la "Empresa de Seguros Internacionales de Cuba" (ESICUBA), dedicada a los seguros necesarios para el desarrollo del comercio exterior, miembro de organizaciones internacionales y ejecutora de las reclamaciones y reaseguros necesarios. La Ley 1100 de 1963 representó, la culminación del proceso unificador y un momento singular en la aplicación de los principios de universalidad, solidaridad, comprensividad e integridad en el Sistema de Seguridad Social. Aspectos fundamentales regulados por la Ley 1100 de 1963, la que se distinguió por: 
- Reafirmó la responsabilidad del Estado en el cumplimiento de las obligaciones derivadas del Sistema de Seguridad Social y el principio de exención de cotizaciones $u$ otras contribuciones por el trabajador y el jubilado,

- Amplió la protección al 100\% de los trabajadores asalariados, incluyendo a los asalariados del campo y a sus familiares,

- Estableció un régimen coherente de prestaciones, articulándolas para asegurar su disfrute sin interrupción,

- Comprendió entre las contingencias cubiertas el accidente de trabajo y la enfermedad profesional, abandonando la antigua teoría del "riesgo profesional" y adoptando un criterio social en la prevención, asistencia y rehabilitación,

- Abarcó la maternidad,

- Incluyó en el cuadro de las prestaciones a la enfermedad común y el accidente de origen común, cuyo seguro social no existía antes en Cuba,

- Reconoció a los fines de la seguridad social los tiempos de servicios prestados en cualquier actividad laboral en todo tiempo.

Ya para el año 1964, inicia sus actividades en el país la "Empresa Nacional de Seguros" (ENSEG), bajo el régimen de financiamiento presupuestario, con las funciones de atender los negocios traspasados por la Oficina de Control, fiscalizar y atender las compañías extranjeras intervenidas, comprobación contable de las que se encontraban en liquidación y nacionalización e integración de las 13 compañías cubanas que quedaban en el sector privado. En 1968, la Ofensiva Revolucionaria elimina la actividad de los corredores de seguro. La Resolución 330/1970 del Banco Nacional de Cuba disuelve en 1970 la ENSEG, asumiendo ESICUBA las carteras de seguros que poseían determinada incidencia en la economía del país.

ESICUBA desde su creación brindó cobertura a todos los riesgos vinculados a la economía exterior del país - la aviación, los buques mercantes y pesqueros, las cargas del comercio exterior, las propiedades cubanas en el extranjero (embajadas, consulados, etc.) y otros de similar naturaleza. Sin embargo, en la medida en que el Estado pasaba a ser dueño de los medios de producción, asumía a su cuenta (a cuenta del Presupuesto del Estado) más y mayores riesgos sin intervención del mecanismo financiero del seguro y sólo aquéllas propiedades que se vinculaban a terceros no cubanos continuaron necesitando protecciones de seguros. Durante la década de los 80 comenzaron a resurgir los intereses extranjeros y la actividad reaseguradora de ESICUBA había alcanzado cierto nivel en el mercado internacional. Con el objetivo de agilizar sus operaciones internacionales, adoptar un estilo de trabajo más comercial y desvincular claramente sus obligaciones de las obligaciones del Estado, a partir de 1987 ESICUBA se transformó en una sociedad mercantil adoptando la denominación social de Seguros Internacionales de Cuba, S.A. y manteniendo las siglas ESICUBA como nombre comercial.

Desde 1996 y durante siete años operó "Aseguradora del Turismo, La Isla S.A.", la que se especializó en seguros generales asociados al sector del turismo, sociedad liquidada en el 2003, asumiendo ESICUBA las obligaciones pendientes. 
Igualmente, funcionó algunos años la "Reaseguradora de la Habana, S.A.", quien se encargó de colocar en el mercado externo los riesgos cubiertos por las aseguradoras cubanas, asumiendo igualmente ESICUBA la tarea de continuarla. Operó durante varios años como corredor de seguros la compañía cubana de capital mixto cubano-inglés "Heat Lambet de Cuba, S.A.". En 1996 se crea "Asistencia al Turista S.A.", (ASISTUR), la cual a su vez opera igualmente como Compañía de Asistencia.

Funcionaron más de mil agentes de seguros, fundamentalmente personas naturales, realizando su labor de intermediación entre las aseguradoras y los clientes. Operando como entidades auxiliares de seguros, INTERMAR S.A., SEPSA y Registro Central de Buques, que se dedicaron, entre otros, a los servicios de inspección, tasación y ajuste de averías a los efectos del seguro. Seis sucursales de compañías extranjeras de seguro de vida fiscalizadas, que después del proceso de nacionalización operado en Cuba en los años 1960 a que hicimos referencia, se mantienen en el país cumpliendo con las obligaciones contraídas hasta esa fecha, pero sin concertar nuevos contratos. También mantienen su presencia en este mercado, dos compañías reaseguradoras: una francesa, "La Intercontinental de Reaseguros" (dependencia de la Caja Central de Reaseguros de Francia), y la "Reaseguradora de las Américas" (casa matriz Munich Re de Alemania).

El 11 de diciembre de 1978 se decide la creación de la "Empresa del Seguro Estatal Nacional" (ESEN) actualmente renombrada "Empresa de Seguros Nacionales" (mantiene las siglas ESEN), la cual tiene como objetivo fundamental desarrollar los distintos tipos de seguros nacionales, especializándose en los seguros personales, de responsabilidad civil y de bienes. La Ley 1100 de 1963, solo comprendía al trabajador y su familia. Pero el nuevo reto consistía en concebir la seguridad social como un sistema que garantizara la protección con la más amplia cobertura para el trabajador, su familia y también aquella parte de la población, cuyas necesidades esenciales no estuvieran aseguradas o que por sus condiciones de vida o de salud requiriera esa protección y no pudiera solucionar sus dificultades sin ayuda de la sociedad. Respondiendo a ello, se concibió la regulación de un sistema integrado por dos regímenes: el de seguridad social y el de asistencia social que, en conjunto, formaran un tono armónico capaz de garantizar, como lo expresa la Constitución de la República, que "no haya persona incapacitada para el trabajo que no tenga medios decorosos de subsistencia". ${ }^{10}$

Considerándose por los autores que con el cambio de sistema social en el país, el Estado comenzó a dictar normas que dieron una mirada a la protección de los recursos naturales, entre estas la Ley de Reforma Agraria y otras que han estado dirigidas a disfrutar de un desarrollo sustentable entre las transformaciones sociales y el hombre, pero no han estado aún dirigidas a pesar de existir una legislación en materia ambiental adecuada a establecer el seguro ambiental dentro

10 Consultar en el sitio web del MINISTERIO DE JUSTICIA de la República de Cuba, www.gacetaoficial.cu, la Constitución de la República de Cuba. 
del ordenamiento jurídico interno, que tribute al desarrollo sustentable del hombre con la naturaleza.

\section{2.- EL MARCO JURÍDICO DENTRO DEL DERECHO INTERNO EN CUBA DE LA POLÍTICA ASEGURADORA}

Si tomamos en cuenta un primer análisis sobre a que se le ha denominado contrato, tenemos que para el Derecho Romano no es un cuerpo jurídico homogéneo con una orientación uniforme, obra de un legislador, sino el resultado de una larguísima evolución histórica que pudiera iniciarse en el año 753 a.C. ${ }^{11}$; partiendo de lo anterior, se discute si los romanos entendieron el contrato como una forma genérica productora de obligaciones o bien si, en realidad, conocían nada más ciertos contratos especiales. Demofilo de Buen ${ }^{12}$, afirma que del Digesto, atribuido a Ulpiano, se infiere una concepción de contrato que, según ella, contrato es la convención productora de acción, por tener nombre de contrato o causa civil de obligar. Del mismo Digesto, se invoca un texto, del cual se desprende la idea de que hay contrato cuando hay cambio de promesas o promesas cambiadas, pero en oposición a esto, hay otro texto, del mismo, que dice que hay contrato donde hay cambio de una prestación por una promesa.

Por las diversas acepciones que se daban del contrato, afirma Messineo ${ }^{13}$. que el contrato ha sido un paradigma general y abstracto, susceptible de acoger cualquier contenido al subrayar la variedad temporal espacial del concepto: asimismo, dice Messineo " El concepto moderno del contrato se deriva no del "contactua" de los romanos, sino del nudo pacto (convenio) reconocido por el derecho pretoría que originalmente, es decir, en el derecho romano más antiguo indicaba el elemento voluntario y no lo que los romanos llamaban "contractus", que era el vínculo que mediaba entre dos personas, tuviese éste su origen en un hecho voluntario o en otro hecho no voluntario, y era, además, un vínculo que se producía tan sólo en relación a un contenido determinado al cual correspondían figuras igualmente determinadas de contrato. Sólo aquellas determinadas figuras de contrato engendraban acción, esto es, eran reconocidos por el ordenamiento jurídico y protegidas contra su incumplimiento". ${ }^{14}$

Cuestiones estas que nos llevan a analizar el contrato de seguro, desde su génesis económica hasta la arista jurídica, en particular la relacionada con los recursos naturales.

\footnotetext{
${ }^{11}$ RIMLI. Eugene Th. Historia Universal Ilustrada. T.I pp.220

12 Ensayo sobre "El concepto del Contrato". Boletín del Instituto de Legislación Comparada y Derecho Internacional. No. 1 Julio- Diciembre 1944. pp. 61-63. Panamá

${ }_{13}$ MESSINEO, Francesco. Doctrina General del Contrato.

14 Ibidem No. 13.
} 
2.1.- El Seguro: En sentido económico es la cobertura recíproca de una necesidad fortuita y valorable, relativa a múltiples economías amenazadas de igual modo, así que puede afirmarse que sin mutualidad o cobertura recíproca no hay seguro. Esta cobertura recíproca puede realizarse por dos sistemas: a) Por el sistema de reparto, b) Por el sistema de capitalización. ${ }^{15}$

2.2.- Las Funciones del seguro: posee cuatro funciones, desglosadas en:

La función social de sustituir la ansiedad paralizadora de las actividades por la seguridad.

La función preventiva de los riesgos, a través de las instrucciones que los aseguradores imponen a los asegurados para evitar o aminorar los siniestros.

Función de indemnización o de capitalización, si se produce el evento.

Función financiera, mediante la inversión de las sumas recaudadas en forma de primas o de cuotas, que pueden oscilar desde una actividad especulativa a una actividad de inversión selectiva, de acuerdo con la planificación estatal del desarrollo económico- social. ${ }^{16}$

2.3.- El Contrato de Seguro: Es aquel por el que el asegurador se obliga, mediante el cobro de una prima y para el caso de que se produzca el evento cuyo riesgo es objeto de cobertura, a indemnizar, dentro de los límites pactados, el daño producido al asegurado, $o$ a satisfacer un capital, una renta $u$ otras prestaciones convenidas. Denominado también como Póliza donde se entran a delimitar las condiciones de dicho acto contractual. ${ }^{17}$

En Cuba como ya citáramos con anterioridad se realiza a través de la ESEN y de ESICUBA, como de otras Cias. aseguradoras internacionales que intervienen en el comercio internacional domiciliadas en el país o fuera de fronteras, las que se ocupan de comercializar la póliza, bajo la tutela administrativa del Ministerio de Finanzas y Precios. En el derecho interno analizamos su tracto legal, aparece recogido en el Código de Comercio, norma jurídica aplicada en Cuba desde Ultramar, la que estableció en su artículo 380, definiendo que será mercantil el contrato de seguro si fuere comerciante el asegurador, y el contrato, a prima fija o sea, cuando el asegurado satisfaga una cuota única o constante como precio o retribución del seguro. Contratos conocidos como de seguros sobre la vida, por seguros de vida industrial o popular concertados por asegurados individuales con las compañías de seguros nacionalizadas o confiscadas.

Fueron liquidados a virtud de lo dispuesto en las Leyes 1192 y 1193 de 1966. Estas operaciones del seguro mercantil realizadas en el ámbito interno por la empresa nacional de seguros en ese momento (ENSEG) y en el ámbito

\footnotetext{
${ }^{15}$ Consultar en la página web del MINISTERIO DE JUSTICIA, en el sitio de la gaceta oficial de la República de Cuba, www.gacetaoficial.cu, el Decreto Ley No. 263, Contrato de Seguro.

${ }^{16}$ Ver el material de pregrado relacionado con el Derecho Financiero Tributario, utilizado en la carrera de Derecho.

${ }^{17}$ Consultar en la página web del MINISTERIO DE JUSTICIA, en el sitio de la gaceta oficial de la República de Cuba, www.gacetaoficial.cu, el Decreto Ley No. 263, Contrato de Seguro.
} 
internacional por la Empresa internacional de seguros (ESICUBA), ambas estatales, creadas mediante las resoluciones 1401 y 416 de 31 de 1963 respectivamente del extinguido Ministerio de Hacienda. Dichas empresas se hallaban vinculadas a la Banca Nacional de Cuba, según lo dispuesto en la ley 1298 de 1975, artículo 28, proponiendo y ejecutando la política y planes de seguros en el ámbito nacional. ${ }^{18}$

Con el proceso revolucionario y la política de institucionalización aplicada en el país, se aprueba la Ley No. 59, Código Civil, quien en su artículo 449, definiría por el contrato de seguro, la entidad aseguradora se obliga a pagar una indemnización o a efectuar alguna otra prestación hasta el total de la suma o valor asegurado, al ocurrir alguno de los acontecimientos previstos en el mismo: y el asegurado a pagar una prima calculada de conformidad con las tarifas establecidas. El artículo 449.1. El seguro voluntario se rige por las disposiciones del presente código y por aquellas dictadas por el organismo correspondiente, contentivas de las condiciones generales y especiales y las tarifas aplicables a cada tipo de seguro. 2, El seguro obligatorio se rige por las disposiciones de la ley que lo crea y supletoriamente por las que se establecen en este Código. ${ }^{19}$

Con posterioridad se decide fijar en una norma independiente al contrato de seguro, promulgándose el Decreto Ley No. 263, dando otra impronta a la actividad del seguro, en el artículo 5 de esta norma jurídica se establece, que el seguro es aquel por el cual la entidad de seguros se obliga, mediante el cobro de una prima, a garantizar el interés del asegurado o del beneficiario en cuanto a las consecuencias que resulten del riesgo cubierto por el contrato. ${ }^{20}$

El Ministerio de Finanzas y Precios, organismo encargado de la actividad, dicta la resolución No.8, actual reglamento en materia aseguradora en el país, de la que se coligen los ramos de seguro establecidos en el país que son: bienes; personales; de Responsabilidad Civil; $y$ otros, por lo que podemos colegir los autores que el seguro ambiental, la legislación cubana no le recoge, a pesar de ser esta una de las políticas internacionales en materia ambiental de que el Estado cubano es parte dentro del denominado Derecho Ambiental Internacional. Considerando además por los autores de la importancia que reviste este contrato para el sector empresarial, y para la economía del país en la implementación de los lineamientos, relacionados con la política medioambiental y la monetariocrediticia.

La teoría del seguro, nos señala que tiene como función la de reponer al asegurado, tras un siniestro, en una situación personal o patrimonial lo más próxima a la anterior a sufrirlo; o, sí ello no es posible, darle una compensación

\footnotetext{
${ }^{18}$ Consultar el Código de Comercio. Disponible en el sitio web del MINISTERIO DE JUSTICIA de la Republica de Cuba. www.minjus.cu

${ }^{19}$ Consultar la página web www.gacetaoficial.cu, donde aparece hospedada la Ley No. 59, Código Civil.

${ }^{20}$ Consultar en la página www.gacetaoficial.cu, del MINISTERIO DE JUSTICIA en la República de Cuba, donde se encuentra hospedado el Decreto Ley No. 263, Sobre el Seguro.
} 
económica que atenúe los efectos del daño. Debe observarse que se habla de compensación económica, nunca de negocio, ya que la naturaleza del seguro rechaza que de él pueda obtenerse beneficio, pues incentivaría el fraude.

Una primera clasificación del seguro podría establecerse así: seguros personales: vida, accidentes, etc., seguros de daños: incendio, robo, transporte, etc. El seguro se basa en la existencia de la cadena riesgo-siniestro-daño que consiste en: Riesgo: la posibilidad de que suceda un evento futuro que pueda dañar el objeto del seguro. Siniestro: materialización del riesgo (si aseguramos un cargamento contra roturas, éstas son el siniestro). Y el Daño: el perjuicio producido a consecuencia del siniestro, susceptible de cuantificación (en mercancías se le conoce también como avería). Es intención de los autores opinar en relación a algunas cuestiones recogidas por la norma que puedan estar relacionadas con el seguro ambiental, que son en relación con los riesgos cubiertos al ser variados, por ejemplo:

- $\quad$ Incendio, rayo o explosión, cualesquiera que sea su origen.

- Terremoto, temblores de tierra, erupción volcánica, huracán, ciclón, manga de viento, granizadas y tormentas.

- Hundimiento o corrimiento de tierra.

- Inundación por cualquier causa.

- Escape de agua debido a cualquier causa imprevista.

- Desplome o derrumbe de paredes, techos o estructuras del local asegurado o donde se encuentren los bienes asegurados. ${ }^{21}$

De aquí a criterios de los autores que exista un nexo vinculante con el derecho del medio ambiente y dentro de este con la responsabilidad ambiental, la inspección ambiental, la auditoría ambiental y la comisión de daños, como parte del desarrollo sostenible que tanto se aboga como política ambiental por parte de la Administración Pública de Cuba en el nuevo modelo económico que en el siglo XXI se implementa en el país.

\section{3.- EL DERECHO DEL MEDIO AMBIENTE}

Consideran los autores que la historia medioambiental de la Tierra y de la humanidad es tan moderna como la propia preocupación ambiental. Lo corrobora la obra científica de Bailes, Caracciolo, Walter, Ruffolo, y Environmental History, quienes plantean la dificultad metodológica y la imposibilidad de separación de los problemas medioambientales y de gestión, en lo que se refiere a la sociedad y a sus instituciones. ${ }^{22}$ En este estudio ambiental, sus componentes e interrelaciones

\footnotetext{
${ }^{21}$ Consultar el libro sobre la EMPRESA Y EL EMPRESARIO EN CUBA. Publicado por la ONBC. 2000. En el capitulo relacionado con el Seguro en Cuba.

${ }^{22}$ CAFERRATA, Dr. Néstor A. Profesor e investigador sobre Derecho Ambiental. Director de la Revista Derecho Ambiental. Abeledo Perrot. Argentina. Quien en su libro científico titulado Introducción al Derecho Ambiental, realiza una descripción epistemológica sobre los orígenes del
} 
es un tema de larga data remontado a la antigüedad con los primeros biólogos y naturalistas, como Aristóteles, Heráclito de Efeso, y Anaximandro. Con el inicio de las ciencias modernas, bajo el modelo naturalista, encontramos a fisiologistas, como René Antoine Ferchault de Réaumur, y Antoni Van Leeuwenhoek. Estudiosos a nivel geográfico, como el naturalista y geógrafo Alexander Von Humboldt, y entre los evolucionistas a Jean Baptiste Monet.

Por lo tanto la historia general y la económica, de tradición humanísticohistoricista, previó afectaciones para el siglo $\mathrm{XX}$, como portador de peligros, insertó a la especie humana en el magma complejo de un medioambiente en tensión, el material científico "Les suisses et l'environnement", hace una documentación histórica a partir del siglo XVIII, considerando el punto de partida de los cambios ambientales a la industrialización.

La ecología iniciada por Humboldt y los aportes de Wallace y Darwin. Y de otras propuestas de filósofos, que como Holbach señalaron:" "cuando los hombres se juntaron entre sí para vivir en sociedad, hicieron ya sea formal o tácitamente un pacto, por el cual se obligaron a hacerse mutuos servicios y a no dañarse". La diversidad que existe entre los seres (humanos) hace que reine entre ellos una desigualdad que es la base de la sociedad... La justicia se llama también equidad porque impide el que cada cual use del ascendiente que la desigualdad de naturaleza o industria le ha dado para dañar a los demás. Engels, en su obra "La dialéctica de la naturaleza", declaró preocupaciones tratando con convicción la gravedad de las acciones humanas irreflexivas e ignorantes sobre la naturaleza,

derecho del medioambiente, y quienes han sido en el ahora de Latinoamérica sus principales precursores.

${ }^{23}$ MAXIMILIANO MARTIN, Dr. Leandro. Donde en su obra científica nos refiere apuntes historiográficos sobre los orígenes del medio ambiente como ciencia del derecho y su interrelación con otras ciencias, destacando las obras científicas relacionadas con el tema como: "De anima", "Parva naturalia", "Historia de los animales y Las partes de los animales" Filósofo griego, evolucionista y observador del cual se mencionan varias obras pero solo se da por cierta la autoría de la denominada "De la Naturaleza de las cosas". Filósofo, Matemático y Astrónomo Griego, natural de Mileto, discípulo de Tales, sostenía que los seres humanos nacen de los animales y la evolución de las especies desde la vida marina. Sus observaciones son principalmente descritas en "Sur la digestión des oiseaux"; demostró la naturaleza química del proceso de digestión animal, aisló el jugo gástrico y concibió las primeras experiencias de la digestión in vitro. Leeuwenhoek, fue un observador, tallador de lentes, careciente de formación científica pero pionero en varios descubrimientos relativos a los protozoos, los glóbulos roj os de la sangre, el sistema de capilares y los ciclos vitales de los insectos. Naturalista y Geógrafo alemán, graduado en Cs. Económicas, de gran afición por la investigación del mundo natural, a la muerte de su madre en 1799, de quien heredó una cuantiosa fortuna se largo en una aventura ultramarina partiendo junto a botánico francés Aimé Bompland, desde La Coruña con destino a los territorios españoles de ultramar. Durante cinco años exploró Hispanoamérica y los mares e islas del golfo de México. Sus observaciones vinieron a fundar la geografía física y la meteorología. Entre sus descubrimientos se mencionan, la unión del Orinoco y Amazonas. Entre sus obras se encuentran, "La Flora Francesa", en donde utilizó por primera vez la clave dicotómica para clasificar las plantas, y pese a que su labor científica incluye trabajos sobre meteorología, botánica, química, geología y paleontología, Lamarck es particularmente reconocido por sus estudios sobre la zoología de los invertebrados y por su teoría sobre la evolución. Entre otras obras, publicó entre 1815 y 1822 un extenso tratado, en siete volúmenes sobre "Historia natural de los animales invertebrados". 
en el proceso de apropiación de sus recursos, articuló estos desajustes con los de implicación social: "si han hecho falta el trabajo de siglos hasta que hemos aprendido, en cierto modo, a calcular las consecuencias naturales remotas de nuestros actos encaminados a la producción, la cosa era todavía mucho más difícil en lo que se refiere a las consecuencias sociales" 24

La máquina de vapor, fue el inicio del deterioro medioambiental, no permitió la armonía propuesta, no sustentada sólo el conocimiento de las leyes y regularidades del funcionamiento de la naturaleza. ii Este acelerado avance de la ciencia y de la técnica en la era post-industrial, trajo consigo riesgos a la salud y al medioambiente, al utilizar tecnologías que no permiten su control absoluto, y que en ocasiones escapan a la posibilidad de previsión, y a la imputación culposa de sus consecuencias. 25

Por lo que ha resultado necesario por el hombre construir políticas que de una manera u otra le ayuden a mitigar los riesgos al medio ambiente a través de políticas aseguradoras, y es el caso del seguro ambiental. El Derecho Internacional del Medio Ambiente requiere entonces, frente a actividades riesgosas o eventualmente peligrosas llevadas adelante en territorio bajo la jurisdicción de los Estados o bajo sistemas especiales la adopción de medidas especiales ad intra y ex ante, entre ellas como ya citábamos el Seguro Ambiental Obligatorio.

En este sentido consideramos que es importante destacar que hay por lo menos tres pautas esenciales del sistema civil de tutela ambiental, ellas son: a) Responsabilidad Objetiva, b) Reparación en especie y c) Prevención del Daño Ambiental. En relación a la primera pauta, la atribución "sin culpa" es un mecanismo determinante en el sistema de tutela civil del ambiente, debido a que la responsabilidad civil clásica -fundada únicamente en la culpabilidad subjetivaimportó durante mucho tiempo un obstáculo para que los damnificados accedieran fluidamente a la indemnización. "Y máxime en el ámbito de actividades de alto potencial nocivo (por ej: contra el medio ambiente), pero sustraídas en principio a evidencias de culpabilidad, que quedaban por ende fuera del sistema resarcitorio, garantizando al contaminante un margen de provecho, a costa de la seguridad de la población. Por ello la evolución hacia una responsabilidad objetiva por daño ambiental constituye un eficiente mecanismo de internalización, que impone inexorablemente al contaminante el costo de recomposición, operando entonces como sistema de prevención indirecta, ya que la sanción resarcitoria motiva, como

\footnotetext{
${ }^{24} \mathrm{HOLBACH}$, obra citada denominada la Biblia del materialismo en el año 1770 , la cual refleja la necesidad de preservar la naturaleza, papel que juega el hombre por ser un ente transformador en esta. Cuestión aún pendiente por cumplirse en nuestros días, ya que no se ha creado una conciencia jurídica ambiental para transformar las conductas de los hombres en preservar y mitigar la problemática ambiental que hoy impera en el mundo, cuestión esta que con las nuevas tendencias sobre el ciudadano ambiental orientan el camino a revertir esta problemática desde la arista social.

${ }^{25}$ ENGELS, Federico: "Introducción a la dialéctica de la naturaleza". Obras escogidas, Tomo 2, Págs. 57-58. Editorial Ciencias Sociales. La Habana. Cuba.
} 
amenaza o coacción psicológica-económica, a no producir actos antijurídicos, lesivos del medio ambiente".

En el mismo sentido se expresa la Declaración de Río sobre el Medio Ambiente y el Desarrollo8 en su Principio 16, al establecer que "las autoridades nacionales deberían procurar fomentar la internalización de los costos ambientales y el uso de instrumentos económicos, teniendo en cuenta el criterio de que el que contamina debe, en principio, cargar con los costos de la contaminación, teniendo debidamente en cuenta el interés público y sin distorsionar el comercio ni las inversiones internacionales".

En este marco de responsabilidad objetiva, se hace fundamental para los agentes contaminantes -o potencialmente contaminantes9- contar con un seguro para afrontar los costos de la restitución del ambiente dañado, a su estado anterior al acto de contaminación. Esto, desde el punto de vista de la responsabilidad con la que debe obrar cualquier potencial contaminante del ambiente. Desde el punto de vista del Estado, también se vuelve imprescindible establecer la obligatoriedad de contratar este tipo de seguros, para dar cumplimiento al Principio de Prevención, uno de los Principios Internacionales del Medio Ambiente. ${ }^{26}$ Cuestiones estas abordadas en relación a tres principios tributarios para la creación de un régimen comunitario de responsabilidad, entre los que destacan, la cautela, la acción preventiva y la máxima "quien contamina paga". Desde nuestro punto de vista, la responsabilidad civil debe ser un instrumento legal básico para la protección del medio ambiente, como bien de titularidad colectiva, por constituir uno de los mecanismos más idóneos para garantizar la reparación adecuada de los daños que resulten de actividades peligrosas.

Es preciso destacar que el medio ambiente se ha reconocido como bien jurídico, se considera como res nullius, como un bien de dominio público, o como un bien de propiedad privada, pero es considerado por los autores que el medio ambiente es de uso colectivo, aunque responde a intereses de carácter difuso. Es criterio de los autores que en el siglo XXI los problemas ambientales se han agravado más, y no se avizoran soluciones para resolver el actual deterioro ambiental que impera en el mundo y del que Cuba no está ajena, es importante destacar que dentro del derecho interno cubano existen normativas que entran a regular la protección de los recursos naturales, pero es menester reconocer que el sector empresarial estatal y el no estatal están obligados a incrementar la cultura jurídica para poder ser competitivos, pues los empresarios en un gran porciento no tienen cultura del seguro y no lo planifican en sus registros contables, ante la posibilidad de que concurran riesgos.

\footnotetext{
${ }^{26}$ STIGLITZ, G.A.-“El Daño al Medio Ambiente en la Constitución Nacional”, en Responsabilidad por Daños en el Tercer Milenio. Homenaje al Profesor Doctor Atilio Aníbal Alterini, Ed. AbeledoPerrot, 1 997, p. 317 y ss.
} 


\section{4.- EL SEGURO AMBIENTAL EN EL NUEVO MODELO ECONÓMICO CUBANO}

Dentro del proceso de institucionalización, la protección ambiental ha tenido un espacio preponderante desde el texto constitucional, contribuyendo a que en posteriores leyes dictadas por el órgano competente, como parte del derecho sustantivo en materia ambiental, demostrándose que el país dicta acciones protectoras hacia la naturaleza, en correspondencia a los tratados firmados, corroborados hoy con el nuevo modelo económico que se implementa.

En su Capítulo I: Fundamentos Políticos, Sociales y Económicos del Estado, distinguen cuatro ámbitos de incidencia interrelacionados: la protección del medio ambiente como principio constitucional rector de la política económica y social, la función pública de protección ambiental como mandato de acción para el Estado; la protección ambiental como ámbito de atribuciones y competencias, y la protección de los recursos naturales y de todo el rico potencial de la naturaleza como un deber ciudadano. ${ }^{27}$ Monzón Brugera, Rey Santos, Cruz Sardiñas, y Hernández Aguilar consideran, que al amparo de nuestro texto constitucional, cumplir con las exigencias de la protección ambiental y reconocer su relación estrecha con el desarrollo económico y social sostenible, es un mandato para el Estado a través de los órganos competentes en aplicar esta política. Por tanto, su aplicación se instituye como principio constitucional de actuación de los órganos estatales y se convierte en fundamento informador del ordenamiento jurídico. ${ }^{28}$

Este nuevo modelo económico erigido a través de la aprobación de los Lineamientos en el 6to Congreso del Partido Comunista de Cuba, opinan los autores que deberá repensarse un nuevo derecho ambiental, dentro del derecho interno cubano, y dentro de la temática que se aborda, es meritorio significar que el sistema contable del país aún no incorpora en toda su dimensión los riesgos medioambientales, para evaluar responsabilidades, de ahí la importancia que adquieren las organizaciones estatales y profesionales a la hora de definir los hechos medioambientales y marcar las pautas para su reflejo contable, de forma que las empresas conozcan cuál sería la línea de actuación en este campo

\footnotetext{
${ }^{27}$ MONZON BRUGERA, Dra.C. Yailen. Ver Tesis doctoral sobre Derecho Ambiental titulada Manejo Integral de Zonas Costeras. Profesora de la UNIVERSIDAD DE CIENFUEGOS. Republica de Cuba. La autora realiza un análisis sobre el texto constitucional cubano, en relación con la protección de los recursos naturales por parte de las personas naturales y jurídicas, así como las competencias que le corresponden a los órganos de control establecidos dentro del derecho sustantivo cubano.

${ }^{28}$ HERNANDEZ AGUILAR, Msc. Orisel. Consultar el artículo relacionado con los retos ambientales de la Constitución Cubana, publicado por la Sociedad Cubana de Derecho Constitucional y Administrativo, del Proyecto ECOIRE. UNJC. Bajo el titulo de: RETOS Y TENDENCIAS DEL DERECHO AMBIENTAL CONTEMPORÁNEO. Colectivo de autores- ONBC, 2011. Donde se abordan las principales falencias en el texto constitucional en materia ambiental a criterio del autor, del cual coincidimos que se deberá abordar en el momento que se decida por parte del Estado cubano en esta materia. Cuba. Profesora de Derecho Constitucional. Facultad de Ciencias Sociales y Humanísticas. Universidad de Pinar del Rio. Estos autores consideran la necesidad de reformar el texto constitucional en relación con la política ambiental.
} 
mejorando la comparabilidad de la información suministrada, de lo que hoy se denomina en el mundo contable, la contabilidad verde.

Esta deuda legislativa, relacionada con el seguro ambiental, debido a que nuestra legislación no lo establece de manera fáctica, aunque deja abierta en la clasificación de los ramos donde el legislador señala de forma abierta "otros", coligiendo los autores que no está aún definido, factor este muy vinculado a la comisión de daños al ambiente, fundamentalmente de los que proceden de la actuación de las Personas Jurídicas, si tenemos en cuenta que por la obsolescencia tecnológica imperante en el país, podríamos señalar que la industria cubana por su heterogeneidad y muchos años de explotación, no cumple con los estándares internacionales relacionado con el mercado de las Producciones más Limpias, ${ }^{29}$ ocasionando agresión al medio ambiente, sin dejar de reconocer esta comisión también por parte de las Personas Naturales, con el incremento de los pequeños empresarios (Trabajadores por Cuenta Propia), que cada día van en aumento sin cumplirse las buenas prácticas con el medio ambiente.

Es por esto que los autores coinciden que tendrá que repensarse el derecho del medio ambiente con miradas nuevas, la mayor parte del daño ambiental ocurre por causas lícitas y el derecho ambiental lo contempla en la distancia e impasible, que como expresara Rey Santos, parece haber muy pocas dudas sobre el vínculo de la crudeza de estos fenómenos y el actuar humano. No solo por las crecientes indicaciones sobre los cambios climáticos de origen antrópico, sino también por el modo en que el manejo de bosques, humedales, cuencas y otros recursos, contribuye al costo humano y económico de estos fenómenos. Son mega fenómenos de daño ambiental, aunque en una primera mirada no parezcan aprehensibles jurídicamente. ${ }^{30}$ Mandatos legales que no han sido aún cumplidos por el Estado cubano, como el de implementación dentro del ordenamiento ambiental, la regulación de un seguro ambiental obligatorio, relacionado con el ambiente de control, desafíos de la legislación ambiental en este siglo XXI, con la introducción de elementos trasversales u horizontales en la regulación de las distintas esferas específicas del medioambiente, enunciados a nivel de principios y sin un adecuado desarrollo.

No es desconocido que el artículo 27 de la Constitución, consagra la protección ambiental como función pública. Técnicamente, a la vez que se habilitan a los órganos competentes para que intervengan en la protección del medio ambiente inspirados en el desarrollo sostenible, se ordena la aplicación de dicha habilitación con el objetivo de "hacer más racional la vida humana y asegurar la supervivencia, el bienestar y la seguridad de las generaciones actuales y futuras "con lo que la solidaridad en términos de equidad inter e intrageneracional, la racionalidad y la sostenibilidad trascienden al texto constitucional cubano, posición asumida por

\footnotetext{
${ }^{29}$ Consultar el MANUAL DE PRODUCCIONES MÁS LIMPIAS. CITMA. La Habana. Cuba.

30 Consultar la obra científico del Director de Politica Ambiental, del Ministerio de Ciencias, Tecnología y Medio Ambiente, REY SANTOS, MSc. Orlando. Cuba. 2012.
} 
Hernández Aguilar $^{31}$ en sus publicaciones sobre los retos ambientales de la Constitución, que en su actualización deberá contener. Esta protección medioambiental en Cuba es considerada por Monzón Brugera como un mandato de acción para los órganos y organismos estatales, mientras que el deber ciudadano de protección no atañe a todo el medio ambiente que hay que proteger en virtud del concepto jurídico de medio ambiente consagrado en el ordenamiento positivo, sino exclusivamente al ambiente natural. De este modo, queda fuera no solo el ambiente social, sino también el artificial constituido por lo que circunda al hombre y que él mismo ha creado. ${ }^{32}$

El sector empresarial, conocedor de las disposiciones jurídicas reguladoras de políticas ambientales, no son debidamente acatadas por diversas causales o contradicciones, entre las que consideramos los autores al significar: por falta de prioridad del tema ambiental, por inadecuado manejo de los presupuestos o en ocasiones la actividad no es prioridad, otras sí consideran que la poseen relegándola a segundo y terceros planos, sin una adecuada visión de futuro en relación con la disminución o mitigación de los problemas ambientales en diversos escenarios a transformar; los organismos de la Administración Pública que tienen que ejercitar las acciones de control no la ejecutan con la adecuada rigurosidad que el tema amerita; a pesar de que los medios de comunicación social es recurrente el tratamiento de temas medioambientales; pero no concebimos la percepción del riesgo, aspectos validados por Guevara Martínez, Viamontes Guilbeaux, y Rodríguez Coquet, quienes desde el derecho laboral han abordado lo socio-ambiental y sus implicaciones negativas. ${ }^{33}$

Otros autores contrastados en materia de derecho comparado del área latinoamericana como Argentina, Chile, Colombia, México, y los Estados Unidos, y de la Comunidad Europea como Ahumada F., Viguri Pereda, García Castro, quienes consideran que los orígenes del seguro ambiental están dados en atención a que hoy en día, los riesgos medioambientales cobran vital relevancia en la industria de los seguros considerando que éste ha ido evolucionando a través del tiempo y no sólo se aseguran necesidades económicas, derivadas de la actividad empresarial, sino que se asegura también la calidad de vida del individuo. De esta forma, han aparecido nuevos riesgos cuyas implicaciones económicas son desconocidas y no existe un conocimiento científico suficiente

\footnotetext{
${ }^{31}$ HERNANDEZ AGUILAR, Msc. Orisel. Consultar el artículo relacionado con los retos ambientales de la Constitución Cubana, publicado por la Sociedad Cubana de Derecho Constitucional y Administrativo, del Proyecto ECOIRE. UNJC. Bajo el titulo de: RETOS Y TENDENCIAS DEL DERECHO AMBIENTAL CONTEMPORÁNEO. Colectivo de autores- ONBC, 2011. Donde se abordan las principales falencias en el texto constitucional en materia ambiental a criterio del autor, del cual coincidimos que se deberá abordar en el momento que se decida por parte del Estado cubano en esta materia. Cuba. Profesora de Derecho Constitucional. Facultad de Ciencias Sociales y Humanísticas. Universidad de Pinar del Rio.

${ }^{32}$ Ibídem no. 25.

${ }^{33}$ Los autores citados tienen una vasta obra científica relacionada con el derecho de la salud en materia ocupacional, denominado ambiente laboral. Con vivencias relacionadas con lo que concurre en el sector empresarial cubano.
} 
para valorar todos los daños asociados a la ocurrencia de grandes problemas medioambientales del futuro como el cambio climático y la escasez de agua potable. $^{34}$

Si tomáramos como referencia la estructura de una póliza de contaminación, que deberá supeditarse para su formalización al resultado técnico de los cuestionarios previos y auditorías sobre la gestión ambiental de la empresa (auditoría ambiental) realizada en la Comunidad Europea de hoy, constamos que se señala la incidencia de importantes problemas, relativos a lo que debe entenderse por contaminación, daño y perjudicado. De acuerdo a los acuerdos de subscripción entre instituciones aseguradoras y reaseguradoras para la asunción de los riesgos medioambientales. Así, en el ámbito norteamericano, conocido como Plia y, en España llamado Pool Español de Riesgos Medioambientales (asociaciones de aseguradoras), cuyas opiniones conjuntamente con las de la Unión Española de Entidades Aseguradoras y Reaseguradoras (UNESPA), definen la introducción o dispersión en la tierra, mar o aire de materias o formas de energía que produzcan en la calidad de dichos medio un deterioro que resulte peligroso o dañino. Estableciendo dos criterios: a) Que se origine en las instalaciones $o$ en los trabajos, donde debe observarse un comportamiento respetuoso con el medio ambiente, siguiendo una auditoría ambiental previa; b) que se produzca de forma accidental y aleatoria, tanto con carácter repentino como gradual.

Objeto de seguro: incluye el daño emergente y el lucro cesante, con la consiguiente carga de la prueba, así como los gastos de prevención y aminoración. Según el pool, las prestaciones del asegurador se componen de las siguientes partidas:

a) Pago de indemnizaciones por daños personales, materiales y perjuicios consecutivos, definidos con anterioridad y con las limitaciones ya señaladas (supra).

b) Abono de gastos originados para detener, aminorar o neutralizar la contaminación, siempre que se hayan iniciado y afectado (o sean susceptibles de hacerlo) a terceros.

c) Reintegro de gastos efectuados con la finalidad de evitar un riesgo inminente de contaminación.

d) Restitución de las costas judiciales y extrajudiciales o los gastos de la constitución de fianzas.

3) Exclusiones: Entrarían en esta categoría los incumplimientos dolosos como las multas y los daños propios. El pool excluye de la póliza los bienes naturales o con valor medioambiental o ecológico que son difíciles de valorar, pero no por ello deben quedar fuera de cobertura los daños derivados de instalaciones nucleares radioactivas (que poseen su propio seguro), las instalaciones del asegurado (incluyendo la propiedad, posesión o uso de vehículos terrestres, artefactos

\footnotetext{
${ }^{34}$ Consultar tesis en Ciencias Jurídicas y Sociales. UNIVERSIDAD DE CHILE. Escuela de Derecho. Sobre seguro y daño ambiental. Chile: AHUMADA F, Paula. 2007.
} 
volantes o embarcaciones), los daños genéticos en personas, animales o plantas, las reclamaciones por modificaciones en el nivel, caudal o curso de las corrientes o masas de agua subterránea o superficial, los producidos al personal de la empresa, además de los perjuicios puros que no son consecuencia directa de daños personales o materiales sufridos. Por último, se incluyen aquellos daños cuya ocurrencia no podía ser prevista por el asegurado, debido al estado de los conocimientos científicos y técnicos en el tiempo en que aconteció la causa de tales daños, puesto que en las operaciones del cálculo de la prima no se pudieron prever.

4) Delimitación temporal: Tradicionalmente se han configurado con el sistema "claims made", fórmula cuestionada por los tribunales de algunos países. De ahí que actualmente se estén subscribiendo pólizas bajo los principios "primera manifestación verificable", en virtud de los cuales el asegurador cubre los daños declarados, por primera vez, durante la vigencia de la póliza, siempre que no sean consecuencia de causas antiguas sobrevenidas con anterioridad a la fecha del contrato ("contaminación histórica").

5) Delimitación territorial: Será importante delimitar el ámbito geográfico de la aplicación de la póliza. Estipula el pool que debe incluirse toda responsabilidad por daños originados a cualquier país de la Unión Europea (lo que se entiende como responsabilidad por contaminación transfronteriza).

6) Siniestros en serie: Se estima que todos los daños que obedezcan a un mismo siniestro o a una misma causa o causas relacionadas con el mismo, constituyen un único siniestro a los efectos del límite cuantitativo de la póliza.

7) Suma asegurada y límite máximo: Puntos expuestos con anterioridad.

8) Garantías opcionales: En función de la autonomía de la voluntad de las partes contratantes.

9) Cláusulas administrativas: Son los términos que regulan las obligaciones de las partes.

Finalmente, queremos significar que en el año 1997, un grupo de compañías de seguros puso en marcha una iniciativa, en el marco del Programa de las Naciones Unidas para el Medio Ambiente (UNEP), cuyo objetivo consistió en promover la gestión en el sector de seguros. En la actualidad, ya más de 80 aseguradoras de 26 países se han adherido a ella. El plan obliga a realizar una adecuada gestión de riesgos ecológicos, una introducción de consideraciones ambientales en las operaciones internas, así como la realización de revisiones periódicas y la promoción de productos y servicios verdes. En España, podemos constatar el Pool de Riesgos Medioambientales ${ }^{35}$. Con la certificación de las normas ISO 14 001. Hay una experiencia que curiosamente, son las PYMES (Pequeñas y Medianas Empresas) las más interesadas en los seguros de contaminación (como se les conoce popularmente), mientras que las grandes compañías siguen prefiriendo optar por contratar esta garantía dentro de sus

\footnotetext{
${ }^{35}$ VIGURI PEREA, Dr. Agustín. Profesor Titular de Derecho Civil. UNIVERSITAT JAUME I DE CASTELLÓ. Licenciado en Derecho Norteamericano. UNIVERSITY OF PITTSBURGH, USA.
} 
seguros tradicionales de responsabilidad civil como el de carácter forzoso o el de libre contratación y otras clasificaciones entre las que están los seguros de responsabilidad por: derrame de Hidrocarburos u otras sustancias nocivas, de responsabilidad por accidentes nucleares, de responsabilidad civil por contaminación y la póliza de responsabilidad por contaminación asimilada de asociación de aseguradores no marítimos.

4.1.- La política inversionista del derecho mercantil en Cuba y las buenas prácticas ambientales. La primera regulación jurídica post-revolucionaria que trata el tema de la inversión extranjera y en especial de las empresas mixtas, lo fue el Decreto-Ley No. 50, el cual unido a otras normas dictadas por varios organismos de la Administración Central del Estado relativas a cuestiones financieras, de contabilidad, estadísticas, mercantiles y laborales y al viejo Código de Comercio aún vigente, conformaron el régimen jurídico de las inversiones extranjeras. En esta legislación se autoriza por vez primera la creación de las Empresas Mixtas, entidad que se crea cuando por ambos socios se decide crear una asociación en la cual se fijan los pactos y condiciones que se consideren conveniente, mediante un contrato en el que se designarían representantes por ambas partes, por esta norma sólo se permitía que se autorizara el usufructo temporal de terrenos, industrias, o instalaciones, de acuerdo a las regulaciones del Código Civil de 1987.

Empresas Mixtas, que adoptaron las formas de Compañías Anónimas por acciones nominativas, aplicándoles las disposiciones vigentes del Código de Comercio. Teniendo en consideración las limitaciones antes expresadas en la legislación existente y en propia Constitución de 1976, el desarrollo que van teniendo las inversiones extranjeras y la necesidad de llevar a vías de hecho otras formas de estas, que no solo fueran las Empresas Mixtas, era imprescindible que existiera en este sentido un respaldo constitucional, ya que la Constitución cuando se refería a la propiedad estatal era absoluta, sin hacer excepciones, ni excluir ningún medio de producción; de aquí la necesidad de la reforma constitucional de 1992, la que a su vez prepara el camino para los cambios legislativos que con posterioridad se producen. Significando que tenía una mirada mercantil, dejando a un lado la temática ambiental.

Una vez realizados los cambios constitucionales, se crean las bases de la Ley No.77 de 1995 "Ley de la Inversión Extranjera", que regula entre otros aspectos todo lo relativo a las Empresas Mixtas, como una de las formas que puede adoptar la inversión extranjera. Por lo que la actividad del seguro forma parte de los sectores en que pueden ser autorizadas inversiones extranjeras y las personas naturales o jurídicas que se propongan ejercer en tanto: entidades de seguros, sociedades mutuas, corredores de seguros, agentes de seguros y entidades de servicios auxiliares del seguro, deberán obtener como requisito previo a los trámites de registro e inscripción establecidos en la legislación vigente, la autorización o licencia de la superintendencia de seguros. ${ }^{36}$

\footnotetext{
${ }^{36}$ Consultar en el sitio del MINISTERIO DE JUSTICIA de la República de Cuba, en la pagina web www.gacetaoficial.cu, la Ley No. 77, Ley de la Inversión extranjera.
} 
Las entidades de seguros tienen, bajo condiciones competitivas a escala internacional, la primera opción para la cobertura de riesgos a personas naturales o jurídicas extranjeras y a empresas mixtas, cuyos intereses se hayan situado en el territorio de la República de Cuba. Por lo que las empresas mixtas, los inversionistas extranjeros y nacionales en los contratos de asociación económica internacional, y las empresas de capital totalmente extranjero, deben contratar a compañías autorizadas por el Ministerio de Finanzas y Precios para operar en el país los seguros correspondientes sobre bienes.

Las instalaciones industriales, turísticas o de otra clase, o los terrenos que sean dados en arrendamientos por empresas estatales y otras organizaciones nacionales, serán aseguradas por el arrendatario a favor del arrendador. Los servicios de seguros también forman parte de las actividades que desarrollan los concesionarios en las zonas francas y parques industriales, así como los operadores que expresamente obtengan autorización.

Los autores consideran que la Ley de la inversión extranjera en el país refiere que tiene por objeto promover e incentivar la inversión extranjera en el territorio, para llevar a cabo actividades lucrativas que contribuyan al fortalecimiento de la capacidad económica y al desarrollo sostenible del país, sobre la base del respeto a la soberanía e independencia nacionales y de la protección y uso racional de los recursos naturales; y establecer, a tales efectos, las regulaciones legales principales bajo las cuales debe realizarse aquella.

Toda vez que en el artículo 54 de la propia norma establece que la inversión extranjera se concibe y estimula en el contexto del desarrollo sostenible del país, lo que implica que durante su ejecución se atenderá cuidadosamente a la conservación del medio ambiente y el uso racional de los recursos naturales. Nos preguntamos no será importante crear una política aseguradora en materia ambiental, por ser Cuba un país propenso a riesgos ambientales cada vez más intensos ante los cambios climáticos del mundo actual. Nos cuestionamos ¿se realizan buenas prácticas ambientales en todo el desarrollo inversionista del país?, ¿habrá una adecuada cultura ambiental en pos de un desarrollo sustentable por parte de las personas jurídicas y naturales?, son interrogantes de los autores en los que habrá que continuar profundizando en futuras investigaciones sobre el tema.

\section{5.- CONCLUSIONES}

El seguro medioambiental no deberá ser mirado como la única herramienta útil en la tarea de preservar el ecosistema. Es un instrumento que si bien protege el patrimonio estatal o privado e individual de un asegurado ante la generación accidental de un daño al medio ambiente producto de la realización de una actividad, presenta ciertas dificultades en relación a su aplicación que no deben dejarse de lado a la hora de constituir un efectivo sistema de reparación medioambiental. No es recomendable el recurso al seguro obligatorio como 
única medida, debe ser acompañado de otras fórmulas y mecanismos financieros como la constitución de Fondos de Compensación y otras garantías financieras como la constitución de aval o auto seguros que financien determinados fondos financieros.

Regular, a través del Ministerio de Finanzas y Precios y de la Empresa de Seguros Nacionales la normativa correspondiente a los seguros de responsabilidad ambiental, sobre la base de experiencias y legislación internacional en la materia, aplicándolos al contexto cubano, en respuesta a la política en materia ambiental del que el país es Parte.

Concientizar al sector empresarial estatal y no estatal, en la importancia que reviste concertar un contrato de seguro de responsabilidad ambiental, que contribuyan al fortalecimiento de la capacidad económica y al desarrollo sostenible del país, sobre la base del respeto a la soberanía e independencia nacionales y de la protección y uso racional de los recursos naturales; $y$ establecer, a tales efectos, las regulaciones legales principales bajo las cuales debe realizarse aquella.

Revisar la actual legislación ambiental cubana, en pos de su actualización donde se establezcan nuevas pautas relacionadas con la responsabilidad ambiental, el control ambiental y el seguro ambiental. Que tributaran a un mejor control por parte de los órganos y organismos del Estado y de la Administración Pública con competencia y jurisdicción.

Contextualizar la política inversionista de Cuba expresada en la normativa de la inversión extranjera, con las buenas prácticas ambientales, necesitada de la implementación de una política en materia de seguro, que tributen al desarrollo sustentable o sostenible, en armonía con los recursos naturales.

\section{6.- BIBLIOGRAFÍA Fuentes doctrinales}

AYES AMELLES, Gilberto N: Medio Ambiente, Impacto Y Desarrollo, Editorial Científico Técnico. La Habana. Cuba. 2003.

ALENZA GARCíA, J.F., Manual de Derecho Ambiental, Ed. UNIVERSIDAD PÚBLICA DE NAVARRA, Pamplona, España. 2001.

AGUILAR, Gretel y autores. Manual de Derecho Ambiental en Centroamérica. Tomo I. Editora: Unión Mundial de la Naturaleza. CENTRO DE DERECHO AMBIENTAL DE LA UNIÓN MUNDIAL POR LA NATURALEZA. Costa Rica. 2004.

ASPECTOS GENERALES DEL MEDIO AMBIENTE $Y$ DE LA GESTION AMBIENTAL EMPRESARIAL. GRUPO DE TRABAJO ESTATAL. Bahía Habana. Autores: Socarras Stable, Johanna y otros. Cuba. 2009. Producciones más limpia, consumo sustentable. Págs. 49- 59. 
ARNER GUERRE, Dra. Asunción. Responsabilización voluntaria de la industria en la protección medioambiental. Profesora UNIVERSIDAD DE ZARAGOZA. España. 2013.

ASEGURACIÓN DE RIESGO, Serie de Seguro, No.112, New York, pág. 13, 1956. The World Insurance Market Zurich, 1970.

BARRERA GRAF, Dr. Jorge. El Derecho Mercantil en la América Latina. Editora UNIVERSIDAD NACIONAL AUTÓNOMA DE MÉXICO. 1963.

BARRERA, Sergio Luis: Ciencia del Seguro, Editora Columbia SA, La Habana, 1956.

BROSETA PONT, Dr. Manuel. Manual de Derecho Mercantil, Editorial Tecnos S.A, Madrid, España, 1991.

BESA ANTUNES, Dr. Paulo. Artículo: daño ambiental, unma abordagem conceitual. Editora Lumn Juris. Brasil. 2001.

BERNAL PEDRAZA, Dra. Andrea Y. Responsabilidad ambiental de las empresas, un compromiso ético con el desarrollo sostenible. UNIVERSIDAD EXTERNADO DE COLOMBIA. 2009.

BUSTAMANTE ALSINA, Dr. Jorge. Derecho Ambiental. Fundamentación normativa. España. 2010.

BARBATO, N. H.- Derecho de Seguros. Homenaje de la Asociación Argentina de Derecho de Seguros al Profesor Doctor Juan Carlos Félix Morandi, Editora Hammurabi, Buenos Aires, 2001.

BUERES, A. J-KEMELMAJER DE CARLUCCI, A.- Responsabilidad por Daños en el Tercer Milenio. Editora Abeledo-Perrot, Buenos Aires, 1997.

B. CALZÓN: Medio Ambiente y Empresa: Las aseguradoras promueven una póliza de responsabilidad ambiental", Cinco Días, 23-4-2002. España.

CANOVAS GONZALEZ, Dr.C. Daimar. Estudios sobre Derecho del Ambiente. Editora Vadell hermanos. Valencia. Venezuela. 2011.

CAMACHO RODRÍGUEZ, Tatiana, El seguro en Cuba, antecedentes, desarrollo y perspectivas, Revista Cubana de Derecho, No. 33, Año XVII, La Habana. Cuba.

COLECTIVO DE AUTORES: El Seguro como categoría económica en el estado socialista, Editora Universitaria, La Habana, 1988. Cuba.

COLECTIVO DE AUTORES: Sobre el Sistema Financiero, monetario y crediticio en Cuba antes del triunfo revolucionario, Editora Oriente, Santiago de Cuba, 1990. Cuba.

CABEZA ARES, Dr. Alfredo M. Los seguros de responsabilidad civil medioambiental en la obligación de reponer y restaurar el medioambiente alterado, Editora UNIVERSIDAD DE LEÓN, León. España. 2003.

CAFFERATA, Dr. Néstor A., Introducción al Derecho Ambiental, Editora INESemarnat, México D.F., 2004.

CONTABILIDAD AMBIENTAL: medida, evaluación, y comunicación de la actuación ambiental de la empresa. AGENCIA EUROPEA DEL MEDIO AMBIENTE. Barcelona. España. 1999.

COMITÉ CENTRAL PARTIDO COMUNISTA DE CUBA: Lineamientos Económicos del VI Congreso del Partido Comunista de Cuba, Editora Política, 2011. La Habana. Cuba. 
CRUZ SARDIÑAS, Dra. Teresa: El derecho al desarrollo sostenible. Una actualización obligada para la doctrina del Derecho Ambiental. I Congreso Politica, Derecho y Justicia Ambiental. 9na Convención Internacional sobre Desarrollo y Medio Ambiente. La Habana. Cuba. 2013.

CONTABILIDAD MEDIOAMBIENTAL. htpp: //www.5campus.com/medioambiente, consultado 2 de marzo 2013. Educación Superior. La Habana. Cuba. 2004, pág.17.

COLECTIVO DE AUTORES. La empresa y el empresario en Cuba. Editora ONBC. La Habana. Cuba. 2000.

\section{CONVENCIÓN DE LONDRES SOBRE LA LIMITACIÓN DE LA} RESPONSABILIDAD, 1976.

CASTELO, Julio: Diccionario de Seguros. Ed. MAPFRE, S.A., Madrid, 1977.

COLECTIVO DE AUTORES, Nociones de Derecho Mercantil, Editorial Félix Valera, Ministerio de Educación Superior. Cuba.

COLECTIVO DE AUTORES. Derecho de Contratos. UNIVERSIDAD DE LA HABANA. Cuba. 2003.

CIOLLARO, J.A.-Seguro de Caución. Su problemática actual y soluciones. Guía de modelos de pólizas. Distintos tipos de coberturas, Ed. Centro de Publicaciones Jurídicas y Sociales, Buenos Aires, 1984.

CABANILLAS SÁNCHEZ, A: La reparación de los daños al medio ambiente, Aranzadi, 1996. España.

CAÑIZARES ABELEDO, Dr. Fernando. Derecho Comercial. Editora Ciencias Sociales. La Habana. Cuba. 2012.

DRNAS DE CLÉMENT, Z.-Fuentes del Derecho Internacional Ambiental, (http://www.acaderc.org.ar/doctrina/articulos/fuentes-del-derecho-internacional-delmedio), 2010.

DÁVALOS FERNÁNDEZ, Dr. Rodolfo - Empresas Mixtas. Regulación Jurídica. Cuba.

\section{DECLARACIÓN INTERNACIONAL DE PRODUCCIÓN LIMPIA.} www.uneptie.org/pc/cp/declaration/homr.htm

DECLARACION DE PRINCIPIOS DE PRODUCCIÓN LIMPIA, Reunión de Ministros de Medio Ambiente del Mercosur. Montevideo, República Oriental del Uruguay. 9 de octubre de 2003.

DE LUGO BENÍTEZ, B: Tratado de Seguros, Ed. ASES SA, Madrid, 1995.

DIEZ PICAZO A y Luis Gullón: Sistema de Derecho Civil. DICCIONARIO JURÍDICO ESPASA. Editorial Espasa. CALPE. Madrid. 1994. JORDANO FRAGA, Dr. J., El Derecho Ambiental del Siglo XXI. Revista Electrónica de Derecho Ambiental, 09, julio 2003. En: http://huespedes. cica.es/aliens/gimadus/09/dcho_amb2_XXI.htm (visitado el 18 de enero de 2009). España.

JAQUENOD DE ZSOGON, Dra. S., El Derecho Ambiental y sus Principios Rectores, $3^{a}$ ed., Editora Dykinson, S.L, 1991. U.S.

LOZANO CUTANDA, Dra. Blanca. Derecho Ambiental Administrativo, 5ta ed, Editora Dykinson, Madrid. España. 2004.

MARTíN MATEO, Dr. Ramón, Manual de Derecho Ambiental, 2da ed, Editora Trivium, S. A, Madrid, España. 2001.

MARK R. GREENE: Riesgo y Seguro. Editora MAPFRE, S.A., España. 
MEILIJ, G.R-BARBATO, N.H.-Tratado de Derecho de Seguros. Contrato de Seguros. Seguros de Daños, Editora Zeus, Rosario, 1975.

MARTÍNEZ ESCOBAR, Manuel, Los Seguros. Editora Cultural, La Habana 1945. MÓDULO: Sistemas de Seguro. Máster sobre el Derecho de los Negocios: sus proyecciones económicas e internacionales. UNIVERSIDADES AUTÓNOMAS DE MADRID Y DE LA HABANA, 1993, Cuba. PROFESOR D. IGNACIO DEL BARCO MARTÍNEZ: Actuario. Universidad Autónoma de Madrid.

HERNANDEZ AGUILAR, MSc. Orisel y ANDINO RUIBAL, MSc. Ana Rosa. Fundamentos jurídicos constitucionales de la gestión ambiental en Cuba. Propuestas para su perfeccionamiento desde una perspectiva integral. I Congreso de Politica, Derecho y Justicia Ambiental. 9na Convención Internacional sobre Desarrollo y Medio Ambiente. La Habana. Cuba. 2013.

HENRÍQUEZ UREÑA, Francisco, La evolución del seguro en Cuba, revista Seguros, La Habana, Año II, No. 3, marzo de 1937, p.26.

PEREZ VAQUERO, Dr. Carlos. Diez claves para entender el Medio Ambiente. UNIVERSIDAD DE VALLADOLID. España. 2012.

SÁNCHEZ-FRIERA GONZÁLEZ, Dra. María del Carmen, La responsabilidad civil del empresario por deterioro del medioambiente, Editora J. M. Bosch, Barcelona. España. 1994.

INSTITUTO DE INFORMACIÓN DEL SEGURO, NEW YORK: Experiencias sobre seguros, p. 9, 1970.

NICHOLAS, Barry: Forcé Majeure and Frustration. In 27. The American Journal of Comparative Law, 1979.

TALLÓN, D: Commentary on the International Sales Law, Italia, 1987. Best's Key Rating Guide, Property-Liability, 1971.

PólIZAS DE SEGUROS DE ESICUBA. Propiedad y Contenidos Transportación de Mercancías

PAVO ACOSTA, Dr.C. Rolando. Marco jurídico del crédito agrícola y el seguro agropecuario. Cuba.

GARRIGUES, Dr. Joaquín. Curso de Derecho Mercantil, Tomo I, 8va Edición, Madrid, España, 1983.

GARRIDO VASQUEZ, Dr.C. Raúl. Las consideraciones ambientales en la toma de decisiones económicas de Cuba. Una actualización. Revista BETSIME. Cuba. 2008.

y autores. Una aproximación a la problemática del comercio y el medio ambiente desde la óptica cubana. EVENTO CIENTIFICO INTERNACIONAL SOBRE DERECHO AMBIENTAL DE LA ASOCIACION NACIONAL DE JURISTAS DE CUBA. 1997.

- ¿La economía verde o la economía del desarrollo sostenible? Retos actuales y respuestas a los lineamientos del 6to Congreso del Partido Comunista de Cuba. I Congreso de Politica, Derecho y Justicia. 9na Convención Internacional sobre Desarrollo y Medio Ambiente. La Habana. Cuba. 2013.

GARCIA CASTRO, Maria José. Requerimiento de los principios de prevención y precaución ambiental: seguro ambiental obligatorio Facultad de Derecho y Ciencias Sociales UNC. UNIVERSIDAD DE CÓRDOVA. Argentina. 2012. 
GARCÍA DE ENTERRÍA, Dr. Eduardo. Curso de Derecho Administrativo. Parte 1 y 2. Editora Félix Varela. La Habana. Cuba. 2007.

GARCINI GUERRA, Dr. Héctor: Derecho Administrativo. Editora Pueblo y Educación.1986. La Habana. Cuba.

RAPA ALVAREZ, Vicente: El Régimen de los Contratos en el Nuevo Código Civil Cubano, Revista Cubana de Derecho, Número 39/89

: Manual de Obligaciones y Contratos, Ed. ENPES, La Habana, 1991,

RODRIGO URÍA Y MENÉNDEZ AURELIO. Curso de Derecho Mercantil, Tomo I, Editorial Civitas S.L, Reimpresión, Madrid, España, 2001.

RUIZ DE VELASCO, Adolfo. Manual de Derecho Mercantil, Editores Deusto S.A., Bilbao, España, 1992

JIMÉNEZ SÁNCHEZ, Guillermo. Derecho Mercantil, Tomo II, 2da ed., corregida, Editorial Ariel, Barcelona, España, 1992.

SÁNCHEZ CALERO, Fernando. Instituciones de Derecho Mercantil, Tomo I, 19na edición, Madrid, España, Editorial Revista de Derecho Privado, 1996.

REY CARO, E.J. et al. Derecho Internacional Ambiental. Nuevas Tendencias, Marcos Lerner Editorial Córdoba, Córdoba, 1998.

VIVANTE, Dr. César. Derecho Mercantil. Tribunal Superior de Justicia Federal. UNIVERSIDAD DE BOLONIA. Italia. Editora Madrid. España. 2003.

WOLTER DEL Río, Germán (1886-1953): Informe y Proyecto de ley de seguros elevado al honorable Presidente de la República por la Comisión Económica. La Habana, 1931.

YANEZ QUIVEIRO, Dr. Manuel. Máster sobre Derecho de los Negocios, Miembro de las Sociedades Cubanas de Derecho Mercantil y Derecho Económico y Financiero. El seguro. Revista Cubana de Derecho. UNJC. Cuba.

VEGA VEGA, Dr. Juan. Cuba, Inversiones Extranjeras. Cuba.

VICENT CHULIÁ, Francisco. Compendio Crítico de Derecho Mercantil, Tomo II, 3era edición, Parte I, Editorial José María Bosch, España, 1991.

VIGURI PEREA, DR. Agustín. Profesor Titular de Derecho Civil. UNIVERSITAT JAUME I DE CASTELLÓ. Licenciado en Derecho Norteamericano. UNIVERSITY OF PITTSBURGH, USA

VIAMONTES GUILBEAUX, Dra.C. Eulalia: Compendio de Legislación Ambiental. Tomo I. Editora Félix Várela. Cuba. UNIVERSIDAD DE LA HABANA. 1998. Cuba.

: Protección de la salud y la calidad de vida. PNUMA-CITMA. La Habana. 1995. Cuba.

VALLS, Mariana y Brill Rossana. Prevención y compensación frente al daño ambiental- El seguro Ambiental. www.cedha.org/docs/doc156-spa.doc. Consultado el día 6 de junio 2011.

\section{Fuentes legales}

Constitución de la República de Cuba. G.O. Extraordinaria no. 3, fecha 31 de enero de 2003.

Código de Comercio vigente en Cuba desde 1889.

Código Civil, Ley No. 59, G.O. Extraordinaria no. 9, fecha 15 de octubre de 1987.

Ley de Reforma Agraria. G.O. Extraordinaria no. 7, fecha 17 de mayo de 1959. 
Ley No. 77, de la Inversión Extranjera. G.O. Extraordinaria no. 4, fecha 6 de septiembre de 1995.

Ley No. 81, del Medio Ambiente. G.O. Extraordinaria no. 7, fecha 11 de julio de 1997.

Ley No. 107, de la Contraloría General de la República de Cuba. G.O. Ordinaria No. , de fecha

Decreto Ley No. 159, De la Auditoría. G.O. Ordinaria No. 20, fecha 3 de julio de 1995.

Decreto Ley No. 165, De las Zonas Francas y Parques Industriales. G. O.

Ordinaria No.26, fecha 22 de julio de1996.

Decreto- Ley 177, Sobre el Ordenamiento del seguro en Cuba, 2 de septiembre de 1977.

Decreto Ley No. 304, De la contratación económica. G.O.O. no. 62, de fecha 27 de diciembre de 2012.

\section{Sitios web consultados}

www.undp.org.cuppdestrategi.htm.Estrategianacionaldecubahttp72.14.207.104sea rchq=cacheOhroEu_oCXcJ El 27 de febrero 2012.

http://www.cinu.org.mx Medio Ambiente y Desarrollo Sostenible.[en línea] El 7 de mayo de 2010.

www.undp.org.cuppdestrategi.htm.Estrategianacionaldecubahttp72.14.207.104sea rchq=cacheOhroEu_oCXcJ El 27 de febrero 2012.

CD rom de la IX Convención Internacional MEDIO AMBIENTE Y DESARROLLO. Julio 2013. La Habana. Cuba. Memorias del evento internacional.

www.cea.assur.org comité europeo de seguros. 